\title{
A Best Proximity Point Result in Modular Spaces with the Fatou Property
}

\author{
Mohamed Jleli, ${ }^{1}$ Erdal Karapınar, ${ }^{2}$ and Bessem Samet ${ }^{1}$ \\ ${ }^{1}$ Department of Mathematics, King Saud University, Riyadh, Saudi Arabia \\ ${ }^{2}$ Department of Mathematics, Atilim University, Incek, 06836 Ankara, Turkey
}

Correspondence should be addressed to Erdal Karapınar; erdalkarapinar@yahoo.com

Received 15 June 2013; Accepted 9 September 2013

Academic Editor: Salvador Hernandez

Copyright (c) 2013 Mohamed Jleli et al. This is an open access article distributed under the Creative Commons Attribution License, which permits unrestricted use, distribution, and reproduction in any medium, provided the original work is properly cited.

Consider a nonself-mapping $T: A \rightarrow B$, where $(A, B)$ is a pair of nonempty subsets of a modular space $X_{\rho}$. A best proximity point of $T$ is a point $z \in A$ satisfying the condition: $\rho(z-T z)=\inf \{\rho(x-y):(x, y) \in A \times B\}$. In this paper, we introduce the class of proximal quasicontraction nonself-mappings in modular spaces with the Fatou property. For such mappings, we provide sufficient conditions assuring the existence and uniqueness of best proximity points.

\section{Introduction and Preliminaries}

Through this paper, we denote by $\mathbb{N}$ the set of positive integers including zero. Let $X$ be a vector space over $\mathbb{R}$. We denote by $0_{X}$ its zero vector. According to Orlicz [1], a functional $\rho$ : $X \rightarrow[0, \infty]$ is said to be modular, if, for any $\operatorname{pair}(x, y) \in X^{2}$, the following conditions are satisfied:

(i) $\rho(x)=0$ if and only if $x=0_{X}$;

(ii) $\rho(-x)=\rho(x)$;

(iii) $\rho(\alpha x+\beta y) \leq \rho(x)+\rho(y)$ whenever $\alpha, \beta \geq 0$ and $\alpha+\beta=1$.

If $\rho$ is a modular in $X$, then the set

$$
X_{\rho}:=\{x \in X: \rho(\lambda x) \longrightarrow 0 \text { as } \lambda \longrightarrow 0\},
$$

called a modular space, is a vector space.

As a classical example of modulars, we may give the Orlicz modular defined for every measurable real function $f$ by

$$
\rho_{\varphi}(f)=\int_{\mathbb{R}} \varphi(|f(t)|) d \lambda(t),
$$

where $\lambda$ is the Lebesgue measure in $\mathbb{R}$ and $\varphi: \mathbb{R} \rightarrow[0, \infty)$ is a function satisfying some conditions. The modular space induced by the Orlicz modular $\rho_{\varphi}$ is called the Orlicz space. For more examples of modular spaces, we refer the reader to [2-4].
Definition 1. Let $X_{\rho}$ be a modular space.

(1) The sequence $\left\{x_{n}\right\} \subset X_{\rho}$ is said to be $\rho$-convergent to $x \in X_{\rho}$ if $\rho\left(x_{n}-x\right) \rightarrow 0$, as $n \rightarrow \infty$.

(2) The sequence $\left\{x_{n}\right\} \subset X_{\rho}$ is said to be $\rho$-Cauchy if $\rho\left(x_{n}-x_{m}\right) \rightarrow 0$, as $n, m \rightarrow \infty$.

(3) A subset $C$ of $X_{\rho}$ is called $\rho$-closed if the $\rho$-limit of a $\rho$-convergent sequence of $C$ always belongs to $C$.

(4) A subset $C$ of $X_{\rho}$ is called $\rho$-complete if any $\rho$-Cauchy sequence in $C$ is $\rho$-convergent and its $\rho$-limit belongs to $C$.

Definition 2. The modular $\rho$ has the Fatou property if $\rho(x) \leq$ $\liminf _{n \rightarrow \infty} \rho\left(x_{n}\right)$ whenever $\left\{x_{n}\right\} \rho$-converges to $x$.

Recently, the existence and uniqueness of best proximity points in metric spaces were investigated by many authors; see $[2,5-14]$ and references therein. In this paper, we introduce the family of proximal quasicontraction nonselfmappings on modular spaces with the Fatou property. Our main result is a best proximity point theorem providing sufficient conditions assuring the existence and uniqueness of best proximity points for such mappings. 
Let $(A, B)$ be a pair of nonempty closed subsets of a modular space $X_{\rho}$. Through this paper, we will use the following notations:

$$
\begin{gathered}
\gamma(A, B):=\inf \{\rho(x-y):(x, y) \in A \times B\}, \\
A_{0}:=\{a \in A: \rho(a-b)=\gamma(A, B) \text { for some } b \in B\}, \\
B_{0}:=\{b \in B: \rho(a-b)=\gamma(A, B) \text { for some } a \in A\} .
\end{gathered}
$$

Definition 3. Let $T: A \rightarrow B$ be a given nonself-mapping. We say that $z \in A_{0}$ is a best proximity point of $T$ if

$$
\rho(z-T z)=\gamma(A, B) .
$$

Clearly, from condition (i), if $A=B$, a best proximity point of $T$ will be a fixed point of $T$.

Definition 4. A nonself-mapping $T: A \rightarrow B$ is said to be a proximal quasicontraction if there exists a number $q \in(0,1)$ such that

$$
\begin{gathered}
\left.\begin{array}{c}
\rho(u-T x)=\gamma(A, B) \\
\rho(v-T y)=\gamma(A, B)
\end{array}\right\} \Longrightarrow \rho(u-v) \\
\leq q \max \{\rho(x-y), \rho(x-u), \\
\rho(y-v), \rho(x-v), \\
\rho(y-u)\},
\end{gathered}
$$

where $x, y, u, v \in A$.

Lemma 5. Let $T: A \rightarrow B$ be a nonself-mapping. Suppose that

(i) $A_{0} \neq \emptyset$;

(ii) $T\left(A_{0}\right) \subseteq B_{0}$.

Then, for any $a \in A_{0}$, there exists a sequence $\left\{x_{n}\right\} \subset A_{0}$ such that

$$
\begin{gathered}
x_{0}=a, \\
\rho\left(x_{n+1}-T x_{n}\right)=\gamma(A, B), \quad \forall n \in \mathbb{N} .
\end{gathered}
$$

Proof. Let $a \in A_{0}$. From (ii), we have Ta $\in B_{0}$. By definition of the set $B_{0}$, there exists $x_{1} \in A_{0}$ such that $\rho\left(x_{1}-T a\right)=$ $\gamma(A, B)$. Again, we have $T x_{1} \in B_{0}$, which implies that there exists $x_{2} \in A_{0}$ such that $\rho\left(x_{2}-T x_{1}\right)=\gamma(A, B)$. Continuing this process, by induction, we obtain a sequence $\left\{x_{n}\right\} \subset A_{0}$ satisfying (6).

Definition 6. Under the assumptions of Lemma 5, any sequence $\left\{x_{n}\right\} \subset A_{0}$ satisfying (6) is called a proximal Picard sequence associated to $a \in A_{0}$. We denote by $P P(a)$ the set of all proximal sequences associated to $a \in A_{0}$.

Definition 7. Under the assumptions of Lemma 5, we say that $A_{0}$ is proximal $T$-orbitally $\rho$-complete if every $\rho$-Cauchy sequence $\left\{x_{n}\right\} \in P P(a)$ for some $a \in A_{0} \rho$-converges to an element in $A_{0}$.
Let $a \in A_{0}$ and $\left\{x_{n}\right\} \in P P(a)$. For all $n \in \mathbb{N}$, We denote

$$
\delta_{p}\left(x_{n}\right):=\sup \left\{\rho\left(x_{n+s}-x_{n+r}\right): r, s \in \mathbb{N}\right\} .
$$

Since $x_{0}=a$, we have

$$
\delta_{p}(a)=\sup \left\{\rho\left(x_{s}-x_{r}\right): r, s \in \mathbb{N}\right\} .
$$

\section{A Best Proximity Point Theorem}

The following lemmas will be useful later.

Lemma 8. Let $X_{\rho}$ be a modular space. Suppose that a nonselfmapping $T: A \rightarrow B$, where $(A, B)$ is a pair of subsets of $X$, satisfies the following conditions:

(i) $\exists a \in A_{0} \mid \delta_{p}(a)<\infty$;

(ii) $T\left(A_{0}\right) \subseteq B_{0}$;

(iii) $T$ is proximal quasi-contraction.

Then, for any $\left\{x_{n}\right\} \in P P(a)$, one has

$$
\rho\left(x_{n}-x_{n+m}\right) \leq \delta_{p}\left(x_{n}\right) \leq q^{n} \delta_{p}(a),
$$

for any $n \geq 1$ and $m \in \mathbb{N}$.

Proof. Let $\left\{x_{n}\right\} \in P P(a)$ and $(s, r) \in \mathbb{N}^{2}$. From the definition of $P P(a)$, for all $n \geq 1$, we have

$$
\rho\left(x_{n+s}-T x_{n-1+s}\right)=\rho\left(x_{n+r}-T x_{n-1+r}\right)=\gamma(A, B),
$$

which implies, since $T$ is a proximal quasi-contraction, that

$$
\begin{array}{r}
\rho\left(x_{n+s}-x_{n+r}\right) \leq q \max \left\{\rho\left(x_{n-1+s}-x_{n-1+r}\right),\right. \\
\rho\left(x_{n-1+s}-x_{n+s}\right), \\
\rho\left(x_{n-1+r}-x_{n+r}\right), \\
\rho\left(x_{n-1+s}-x_{n+r}\right), \\
\left.\rho\left(x_{n-1+r}-x_{n+s}\right)\right\} \\
\leq q \delta_{p}\left(x_{n-1}\right) .
\end{array}
$$

This implies immediately that

$$
\delta_{p}\left(x_{n}\right) \leq q \delta_{p}\left(x_{n-1}\right)
$$

for all $n \geq 1$. Hence, for any $n \in \mathbb{N}$, we have

$$
\delta_{p}\left(x_{n}\right) \leq q^{n} \delta_{p}(a) .
$$

Using the above inequality, for all $n \geq 1$ and $m \in \mathbb{N}$, we have

$$
\rho\left(x_{n}-x_{n+m}\right) \leq \delta_{p}\left(x_{n}\right) \leq q^{n} \delta_{p}(a) .
$$

Lemma 9. Let $(A, B)$ be a pair of subsets of a modular space $X_{\rho}$. Let $T: A \rightarrow B$ be a given nonself-mapping. Suppose that

(i) $A_{0}$ is proximal $T$-orbitally $\rho$-complete; 
(ii) $T\left(A_{0}\right) \subseteq B_{0}$;

(iii) $\exists a \in A_{0}$ such that $\delta_{p}(a)<\infty$;

(iv) $T$ is proximal quasi-contraction;

(v) $\rho$ satisfies the Fatou property.

Then, any sequence $\left\{x_{n}\right\} \in P P(a) \rho$-converges to some $z \in A_{0}$ such that

$$
\rho\left(x_{n}-z\right) \leq q^{n} \delta_{p}(a)
$$

for all $n \geq 1$. Moreover, there exists $w \in A_{0}$ such that

$$
\rho(w-T z)=\gamma(A, B) .
$$

Proof. Let $\left\{x_{n}\right\} \in P P(a)$. From Lemma 8 , we know that $\left\{x_{n}\right\}$ is $\rho$-Cauchy. Since $A_{0}$ is proximal $T$-orbitally $\rho$-complete, then there exists $z \in A_{0}$ such that $\left\{x_{n}\right\} \rho$-converges to $z$. Again, by Lemma 8 , we have

$$
\rho\left(x_{n}-x_{n+m}\right) \leq q^{n} \delta_{p}(a)
$$

for any $n \geq 1$ and $m \in \mathbb{N}$. Letting $m \rightarrow \infty$ in the above inequality and using the Fatou property, we obtain

$$
\rho\left(x_{n}-z\right) \leq q^{n} \delta_{p}(a) \text {, }
$$

for all $n \geq 1$. Now, since $T z \in B_{0}$, by the definition of $B_{0}$, there exists some $w \in A_{0}$ such that $\rho(w-T z)=\gamma(A, B)$.

Now, we are ready to state and prove our main result.

Theorem 10. Suppose that the assumptions of the previous lemma are satisfied. Assume $\rho(z-w)<\infty$ and $\rho(a-w)<\infty$. Then, the $\rho$-limit $z \in A_{0}$ of $\left\{x_{n}\right\} \in P P(a)$ is a best proximity point of T. Moreover, if $u \in A_{0}$ is any best proximity point of $T$ such that $\rho(z-u)<\infty$, then one has $z=u$.

Proof. By Lemma 9, we have

$$
\rho(w-T z)=\gamma(A, B) .
$$

On the other hand, from the definition of $\left\{x_{n}\right\}$, we have

$$
\rho\left(x_{1}-T a\right)=\gamma(A, B) .
$$

Since $T$ is proximal quasi-contraction, we get that

$$
\begin{aligned}
\rho\left(w-x_{1}\right) \leq q \max \{ & \{(a-z), \rho(z-w), \\
& \left.\rho\left(a-x_{1}\right), \rho\left(z-x_{1}\right), \rho(a-w)\right\} .
\end{aligned}
$$

Using Lemmas 8 and 9, we obtain that

$$
\rho\left(w-x_{1}\right) \leq \max \left\{q \delta_{p}(a), q \rho(z-w), q \rho(a-w)\right\} .
$$

Again, from the definition of $\left\{x_{n}\right\}$, we have

$$
\rho\left(x_{2}-T x_{1}\right)=\gamma(A, B) .
$$

Since $T$ is proximal quasi-contraction, we get that

$$
\begin{gathered}
\rho\left(w-x_{2}\right) \leq q \max \left\{\rho\left(z-x_{1}\right), \rho(z-w), \rho\left(x_{1}-x_{2}\right),\right. \\
\left.\rho\left(z-x_{2}\right), \rho\left(x_{1}-w\right)\right\} \\
\leq q \max \left\{q \delta_{p}(a), \rho(z-w), \delta_{p}\left(x_{1}\right),\right. \\
\left.q^{2} \delta_{p}(a), \rho\left(x_{1}-w\right)\right\} \\
\leq q \max \left\{q \delta_{p}(a), \rho(z-w), q \delta_{p}(a),\right. \\
\left.q^{2} \delta_{p}(a), \rho\left(x_{1}-w\right)\right\} \\
=q \max \left\{q \delta_{p}(a), \rho(z-w), \rho\left(x_{1}-w\right)\right\} \\
\text { (from (22)) } \leq \max \left\{q^{2} \delta_{p}(a), q \rho(z-w), q^{2} \rho(a-w)\right\} .
\end{gathered}
$$

Thus, we proved that

$$
\rho\left(w-x_{2}\right) \leq \max \left\{q^{2} \delta_{p}(a), q \rho(z-w), q^{2} \rho(a-w)\right\} .
$$

Continuing this process, by induction, we get that

$$
\rho\left(w-x_{n}\right) \leq \max \left\{q^{n} \delta_{p}(a), q \rho(z-w), q^{n} \rho(a-w)\right\},
$$

for all $n \geq 1$. Therefore, we have

$$
\limsup _{n \rightarrow \infty} \rho\left(x_{n}-w\right) \leq q \rho(z-w) .
$$

Using the Fatou property, we get

$$
\rho(z-w) \leq q \rho(z-w),
$$

which implies, since $q<1$, that $\rho(z-w)=0$; that is, $z=w$. Thus, from (19), we get that

$$
\rho(z-T z)=\gamma(A, B) .
$$

Hence, $z$ is a best proximity point of $T$.

Suppose now that $u \in A_{0}$ is a best proximity point of $T$ such that $\rho(z-u)<\infty$. Since $T$ is proximal quasi-contraction, we obtain that

$$
\begin{gathered}
\rho(z-u) \leq q \max \{\rho(z-u), \rho(z-z), \rho(u-u), \\
\rho(z-u), \rho(u-z)\} \\
=q \rho(z-u) .
\end{gathered}
$$

Since $q<1$, we have $\rho(z-u)=0$, which implies that $u=z$.

Consider now the case $A=B$. In this case, a best proximity point of $T: A \rightarrow B$ will be a fixed point of the self-mapping $T$.

Definition 11. We say that $A$ is $T$-orbitally $\rho$-complete if $\left\{T^{n a}\right\}$ is a $\rho$-Cauchy for every $a \in A$, then it is $\rho$-convergent to an element of $A$. 
Similarly to Ćirić [15] definition, Khamsi [16] introduced the concept of quasicontraction self-mappings in modular spaces.

Definition 12. The self-mapping $T: A \rightarrow A$ is said to be a quasicontraction if there exists a constant $q \in(0,1)$ such that

$$
\begin{gathered}
\rho(T x-T y) \leq q \max \{\rho(x-y), \rho(x-T x), \rho(y-T y), \\
\rho(x-T y), \rho(y-T x)\},
\end{gathered}
$$

for all $x, y \in A$.

From Theorem 10, we can deduce the following result, that is, a slight extension of the fixed point theorem established by Khamsi in [16].

Corollary 13. Consider a self-mapping $T: A \rightarrow A$, where $A$ is a nonempty subset of $X_{\rho}$. Suppose that the following conditions hold:

(i) A is T-orbitally $\rho$-complete;

(ii) $\exists a \in A$ such that $\sup \left\{\rho\left(T^{s} a-T^{r} a\right): s, r \in \mathbb{N}\right\}<\infty$;

(iii) $\rho$ satisfies the Fatou property;

(iv) $T$ is quasi-contraction.

Then, the sequence $\left\{T^{n a}\right\} \rho$-converges to some $z \in A$. Moreover, if $\rho(z-T z)<\infty$ and $\rho(a-T z)<\infty$, then $z$ is a fixed point of $T$. If $u \in A$ is a fixed point of $T$ with $\rho(z-u)<\infty$, then $u=z$.

\section{Acknowledgment}

This work is supported by the Research Center, College of Science, King Saud University.

\section{References}

[1] W. Orlicz, "A note on modular spaces. I," Bulletin de l'Académie Polonaise des Sciences. Série des Sciences Mathématiques, Astronomiques et Physiques, vol. 9, pp. 157-162, 1961.

[2] L. Drewnowski and A. Kamińska, "Orlicz spaces of vector functions generated by a family of measures," Commentationes Mathematicae, vol. 22, no. 2, pp. 175-186, 1981.

[3] M. A. Khamsi, W. M. Kozłowski, and S. Reich, "Fixed point theory in modular function spaces," Nonlinear Analysis. Theory, Methods \& Applications, vol. 14, no. 11, pp. 935-953, 1990.

[4] J. Musielak, Orlicz Spaces and Modular Spaces, vol. 1034 of Lecture Notes in Mathematics, Springer, Berlin, Germany, 1983.

[5] M. A. Al-Thagafi and N. Shahzad, "Best proximity sets and equilibrium pairs for a finite family of multimaps," Fixed Point Theory and Applications, vol. 2008, Article ID 457069, 10 pages, 2008.

[6] J. Anuradha and P. Veeramani, "Proximal pointwise contraction," Topology and Its Applications, vol. 156, no. 18, pp. 29422948, 2009.

[7] M. De la Sen, "Fixed point and best proximity theorems under two classes of integral-type contractive conditions in uniform metric spaces," Fixed Point Theory and Applications, vol. 2010, Article ID 510974, 12 pages, 2010.
[8] C. Di Bari, T. Suzuki, and C. Vetro, "Best proximity points for cyclic Meir-Keeler contractions," Nonlinear Analysis. Theory, Methods \& Applications, vol. 69, no. 11, pp. 3790-3794, 2008.

[9] A. A. Eldred, W. A. Kirk, and P. Veeramani, "Proximal normal structure and relatively nonexpansive mappings," Studia Mathematica, vol. 171, no. 3, pp. 283-293, 2005.

[10] E. Karapinar, G. Petruşel, and K. Tas, "Best proximity point theorems for KT-types cyclic orbital contraction mappings," Fixed Point Theory, vol. 13, no. 2, pp. 537-545, 2012.

[11] S. Karpagam and S. Agrawal, "Existence of best proximity points of p-cyclic contractions," Fixed Point Theory, vol. 13, no. 1, pp. 99-105, 2012.

[12] W. A. Kirk, S. Reich, and P. Veeramani, "Proximinal retracts and best proximity pair theorems," Numerical Functional Analysis and Optimization, vol. 24, no. 7-8, pp. 851-862, 2003.

[13] S. Sadiq Basha, "Extensions of Banach's contraction principle," Numerical Functional Analysis and Optimization, vol. 31, no. 46, pp. 569-576, 2010.

[14] S. Sadiq Basha, "Best proximity point theorems generalizing the contraction principle," Nonlinear Analysis. Theory, Methods \& Applications, vol. 74, no. 17, pp. 5844-5850, 2011.

[15] Lj. Ćirić, "A generalization of Banach's contraction principle," Proceedings of the American Mathematical Society, vol. 45, no. 2, pp. 267-273, 1974.

[16] M. A. Khamsi, "Quasicontraction mappings in modular spaces without $\Delta_{2}$-condition," Fixed Point Theory and Applications, vol. 2008, Article ID 916187, 6 pages, 2008. 


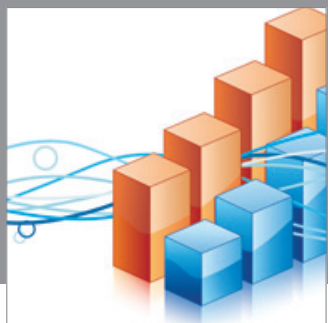

Advances in

Operations Research

mansans

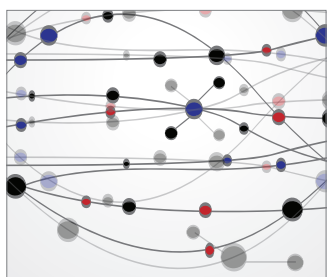

The Scientific World Journal
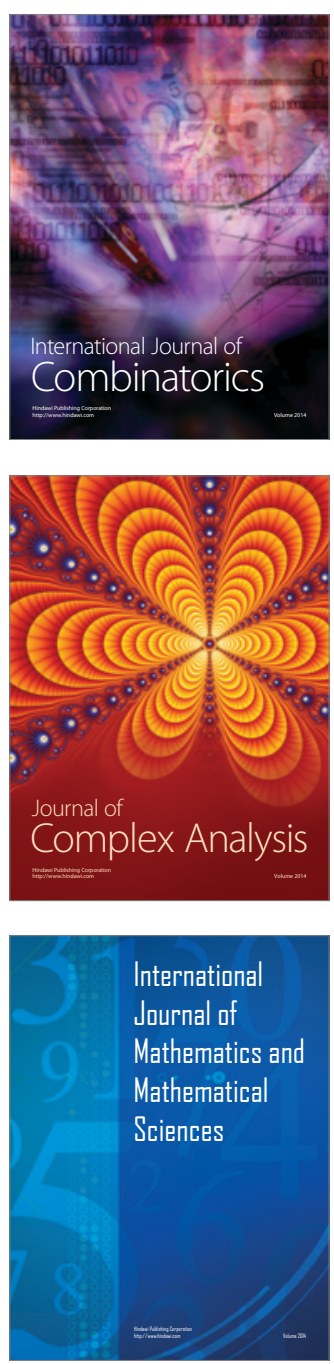
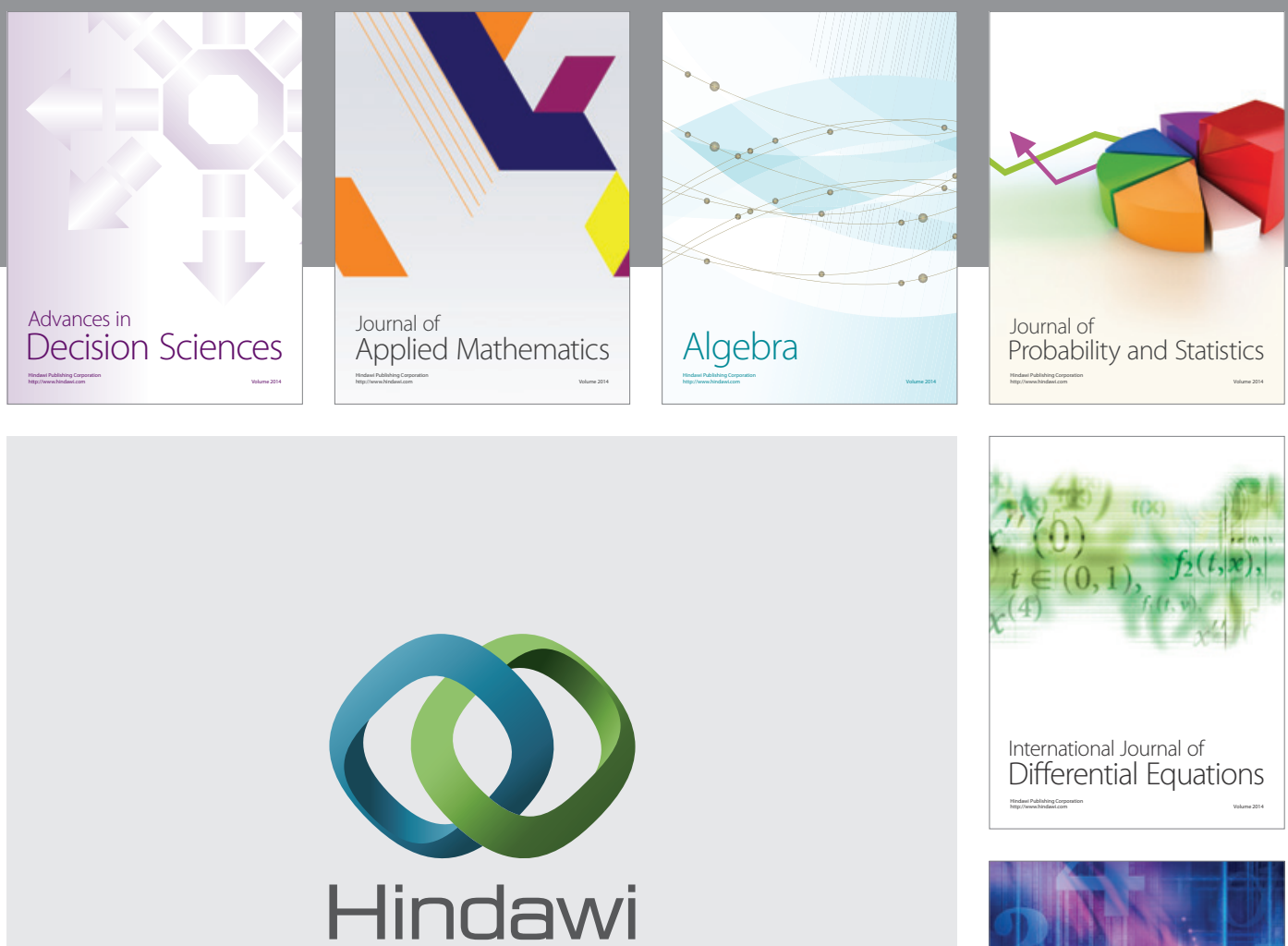

Submit your manuscripts at http://www.hindawi.com
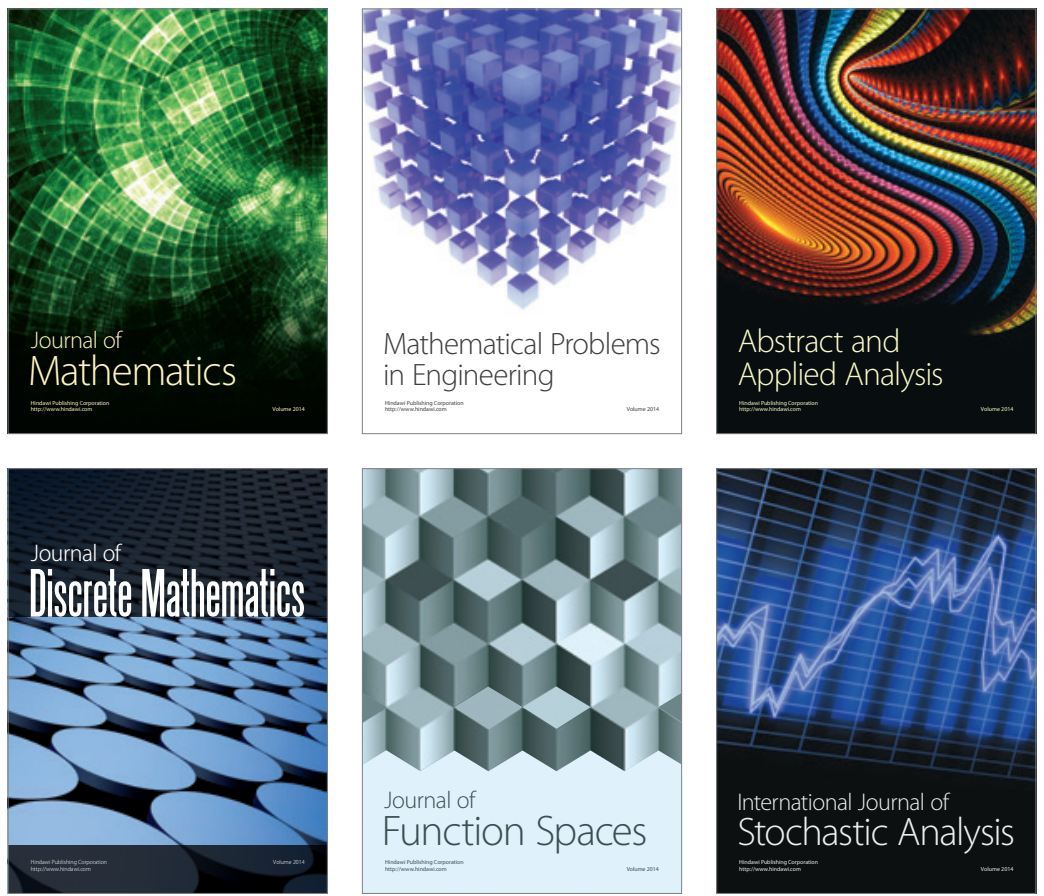

Journal of

Function Spaces

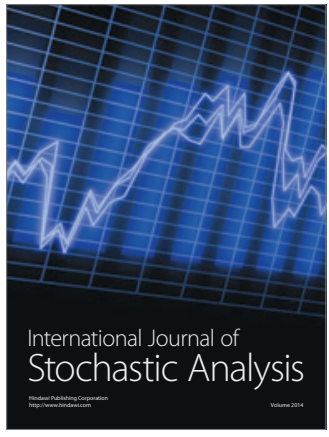

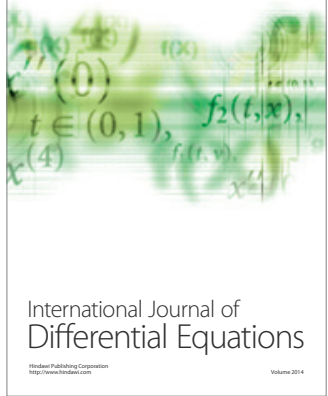
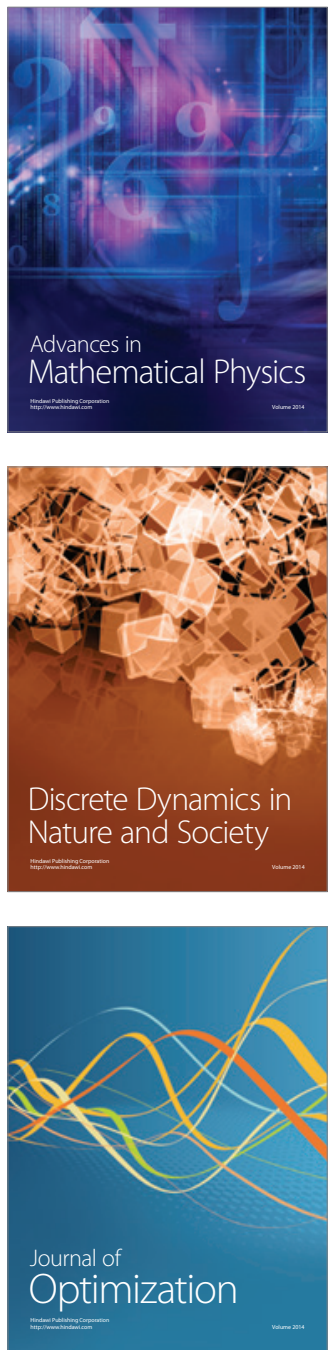